Cilt/Volume: 4

Sayı/Issue: 1

Haziran/June 2015

\title{
BÜEFAD
}

\section{BARTIN ÜNIVERSITESI}

EĞiTIM FAKÜLTESI DERGISI

Uluslararası Hakemli Dergi

\section{AYRI BASIM \\ Yrd. Doç. Dr. Hasbi ASLAN}

Sosyalizasyonun Bir Bileşeni Olarak Sanat ve Sanat Eğitiminin Rasyonellik Görünümü

Rational View of the Arts and Arts Education as a Component of Socialization

BARTINUNIVERSITY

JOURNAL

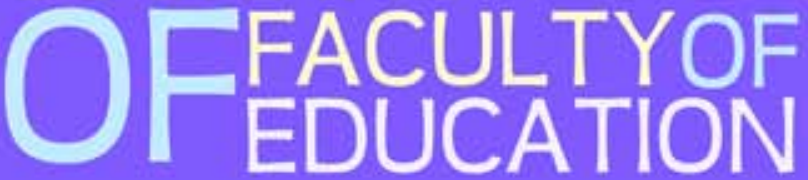

International Refereed Journal 


\title{
BARTIN ÜNIVERsitesi EĞitim FaküLtesi DeRgisi
}

\author{
BaRTIN UNIVERSITY JoURNAL OF FACULTY OF EdUCATION
}

ISSN:1308-7177

Uluslararasi Hakemli Dergi / International RefEREed Journal

\section{Cilt/Volume: 4, Say1/Issue: 1, Haziran/June 2015}

$\underline{\text { Sahibi }}$

Bartın Üniversitesi Eğitim Fakültesi Adına

Prof. Dr. Firdevs GÜNEŞ (Dekan)

Editör

Yrd. Doç. Dr. Sedat BALYEMEZ

\section{Alan Editörleri}

Prof. Dr. Çetin SEMERCi

Doç. Dr. Necati HIRÇA

Doç. Dr. Nuriye SEMERCi

Yrd. Doç. Dr. Ayşe Derya IŞIK

Yrd. Doç. Dr. Ayla ÇETIN DINDAR

Yrd. Doç. Dr. F. Gizem KARAOĞLAN YILMAZ

Yrd. Doç. Dr. Gülsün ŞAHAN

Yrd. Doç. Dr. Harun ER

Yrd. Doç. Dr. Neslihan USTA

Yrd. Doç. Dr. Sinem TARHAN

Yrd. Doç. Dr. Süleyman Erkam SULAK

Yrd. Doç. Dr. Süreyya GENÇ

Yrd. Doç. Dr. Yılmaz KARA

Yabancı Dil Sorumlusu

Yrd. Doç. Dr. Özge GÜN

Yayıma Hazırlık

Arş. Gör. Arzu ÇEViK

Arş. Gör. Ömer KEMiksiz

\section{Sekretarya}

Arş. Gör. Hasan Basri KANSIZOĞLU

\section{Teknik Sorumlular}

Yrd. Doç. Dr. Ramazan YILMAZ

Arş. Gör. Barış ÇUKURBAŞı

\section{İetişim}

Bartın Üniversitesi Eğitim Fakültesi

74100 BARTIN - TÜRKIYE

e-posta: buefad@bartin.edu.tr

Tel: +90 3782235459

Bartın Üniversitesi Eğitim Fakültesi Dergisi (BÜEFAD), yılda iki kez yayımlanan uluslararası hakemli bir dergidir. Yazıların sorumluluğu, yazarlarına aittir.
On Behalf of Bartin University Faculty of Education Prof. Firdevs GUNES (Dean)

Asst. Prof. Sedat BALYEMEZ

Field Editors

Prof. Cetin SEMERCI

Assoc. Prof. Necati HIRCA

Assoc. Prof. Nuriye SEMERCI

Asst. Prof. Ayse Derya ISIK

Asst. Prof. Ayla CETIN DINDAR

Asst. Prof. F. Gizem KARAOGLAN YILMAZ

Asst. Prof. Gulsun SAHAN

Asst. Prof. Harun ER

Asst. Prof. Neslihan USTA

Asst. Prof. Sinem TARHAN

Asst. Prof. Suleyman Erkam SULAK

Asst. Prof. Sureyya GENC

Asst. Prof. Yilmaz KARA

Foreign Language Specialist

Asst. Prof. Ozge GUN

Preparing for Publication

RA. Arzu CEVIK

RA. Omer KEMIKSIZ

Secretary

RA. Hasan Basri KANSIZOGLU

Technical Assistants

Asst. Prof. Ramazan YILMAZ

RA. Baris CUKURBASI

Contact

Bartin University Faculty of Education

74100 BARTIN - TURKEY

e-mail: buefad@bartin.edu.tr

Tel: +90 3782235459

Bartin University Journal of Faculty of Education (BUJFED) is a international refereed journal that is published two times a year. The responsibility lies with the authors of papers.

Kapak: Arş. Gör. Barış ÇUKURBAŞı - Öğr. Gör. Hüseyin UYSAL 


\section{YAYIN DANISSMA KURULU / EDITORIAL ADVISORYBOARD}

Prof. Dr. Hayati AKYOL

Prof. Dr. Hüseyin ALKAN

Prof. Dr. Sebahattin ARIBAŞ

Prof. Dr. Ahmet ARIKAN

Prof. Dr. Safure BULUT

Prof. Dr. Recai DOĞAN

Prof. Dr. Firdevs GÜNEŞ

Prof. Dr. Ahmet GÜNŞEN

Prof. Dr. Bilgin Ünal iBRET

Prof. Dr. Ramazan KAPLAN

Prof. Dr. Firdevs KARAHAN

Prof. Dr. Aziz KILINÇ

Prof. Dr. Ahmet KIRKKILIÇ

Prof. Dr. Murat ÖZBAY

Prof. Dr. Ahmet SABAN

Prof. Dr. Çetin SEMERCI

Prof. Dr. M. Fatih TAŞAR

Prof. Dr. Yavuz TAŞKESENLiGiL

Prof. Dr. Cemal TOSUN

Prof. Dr. Selahattin TURAN

Prof. Dr. Mimar TÜRKKAHRAMAN

Prof. Dr. Selma YEL

Doç. Dr. Bahri ATA

Doç. Dr. Eyyup COŞKUN

Doç. Dr. Erol DURAN

Doç. Dr. Tolga GÜYER

Doç. Dr. Emine KOLAÇ

Doç. Dr. Nuriye SEMERCI

Doç. Dr. Sabri SIDEKLI

Doç. Dr. Çavuş ŞAHIN

Doç. Dr. Neşe TERTEMiz

Doç. Dr. Kubilay YAZICI
Gazi Üniversitesi

Dokuz Eylül Üniversitesi

Adıyaman Üniversitesi

Gazi Üniversitesi

Orta Doğu Teknik Üniversitesi

Ankara Üniversitesi

Bartın Üniversitesi

Trakya Üniversitesi

Kastamonu Üniversitesi

Bartın Üniversitesi

Sakarya Üniversitesi

Çanakkale Onsekiz Mart Üniversitesi

Atatürk Üniversitesi

Gazi Üniversitesi

Konya Necmettin Erbakan Üniversitesi

Bartın Üniversitesi

Gazi Üniversitesi

Atatürk Üniversitesi

Ankara Üniversitesi

Osmangazi Üniversitesi

Akdeniz Üniversitesi

Gazi Üniversitesi

Gazi Üniversitesi

Mustafa Kemal Üniversitesi

Uşak Üniversitesi

Gazi Üniversitesi

Anadolu Üniversitesi

Bartın Üniversitesi

Muğla Sıtkı Koçman Üniversitesi

Çanakkale Onsekiz Mart Üniversitesi

Gazi Üniversitesi

Niğde Üniversitesi 


\section{BU SAYININ HAKEMLERI / REFEREES OFTHIS ISSUE}

Prof. Dr. İbrahim BILGIN

Prof. Dr. Şeref MIRASYEDiOĞLU

Prof. Dr. Yaşare AKTAŞ ARNAS

Doç. Dr. Başaran GENÇDOĞAN

Doç. Dr. Bülent DiLMAÇ

Doç. Dr. Çiğdem KAN

Doç. Dr. Fatma Hülya ÖZCAN

Doç. Dr. Fulya YÜKSEL ŞAHIN

Doç. Dr. Gizem SAYGILI

Doç. Dr. Hakan DÜNDAR

Doç. Dr. H. Elif DAĞLIOĞLU

Doç. Dr. Kaya YILMAZ

Doç. Dr. Kürşat YENILMEZ

Doç. Dr. M. Eyyüp SALLABAŞ

Doç. Dr. Mehmet TEMiZKAN

Doç. Dr. Meliha YILMAZ

Doç. Dr. Melis MiNisKER

Doç. Dr. Muamber YILMAZ

Doç. Dr. Muharrem AKTÜMEN

Doç. Dr. Murat TUNCER

Doç. Dr. Mutlu TÜRKMEN

Doç. Dr. Necati HIRÇA

Doç. Dr. Nurten SARGIN

Doç. Dr. Saide ÖZBEY

Doç. Dr. Soner ÖZDEMIR

Doç. Dr. Süleyman CAN

Doç. Dr. Şebnem KANDIL INGEÇ

Doç. Dr. Şaduman KAPUSUZOĞLU

Doç. Dr. Şenay SEZGIN NARTGÜN

Doç. Dr. Şendil CAN

Doç. Dr. Tahsin ILHAN

Doç. Dr. Tuncer BÜLBÜL

Doç. Dr. Yasin UYSAL

Doç. Dr. Yücel ÖKSÜZ

Doç. Dr. Yüksel GÖĞEBAKAN

Yrd. Doç. Dr. Abdurrahim Can ELDEMIR

Yrd. Doç. Dr. Aynur PALA

Yrd. Doç. Dr. Ayşe ELiÜşÜKK

Yrd. Doç. Dr. Ayşe GÜLER

Yrd. Doç. Dr. Begüm YALÇINKAYA

Yrd. Doç. Dr. Burçin GÖKKURT

Yrd. Doç. Dr. Demet ZAFER GÜNEŞ
Mustafa Kemal Üniversitesi

Başkent Üniversitesi

Çukurova Üniversitesi

Atatürk Üniversitesi

Konya Necmettin Erbakan Üniversitesi

Fırat Üniversitesi

Anadolu Üniversitesi

Yıldız Teknik Üniversitesi

Süleyman Demirel Üniversitesi

Kırıkkale Üniversitesi

Gazi Üniversitesi

Marmara Üniversitesi

Eskişehir Osmangazi Üniversitesi

Yıldız Teknik Üniversitesi

Mustafa Kemal Üniversitesi

Gazi Üniversitesi

Mustafa Kemal Üniversitesi

Bartın Üniversitesi

Gazi Üniversitesi

Fırat Üniversitesi

Bartın Üniversitesi

Bartın Üniversitesi

Konya Necmettin Erbakan Üniversitesi

Gazi Üniversitesi

Kırıkkale Üniversitesi

Muğla Sıtkı Koçman Üniversitesi

Gazi Üniversitesi

Abant İzzet Baysal Üniversitesi

Abant İzzet Baysal Üniversitesi

Muğla Sıtkı Koçman Üniversitesi

Gaziosmanpaşa Üniversitesi

Trakya Üniversitesi

Gazi Üniversitesi

Ondokuz Mayıs Üniversitesi

İnönü Üniversitesi

Çanakkale Onsekiz Mart Üniversitesi

Celal Bayar Üniversitesi

Bartın Üniversitesi

Kırıkkale Üniversitesi

Çanakkale Onsekiz Mart Üniversitesi

Bartın Üniversitesi

İstanbul Sabahattin Zaim Üniversitesi 
Yrd. Doç. Dr. Emrullah YILMAZ

Yrd. Doç. Dr. Erol BARIN

Yrd. Doç. Dr. Fatma YAŞAR EKici

Yrd. Doç. Dr. Funda NALBANTOĞLU YILMAZ

Yrd. Doç. Dr. Güliz AYDIN

Yrd. Doç. Dr. Hatice Sezgi SARAÇ

Yrd. Doç. Dr. Hicran ÇETIN GÜNDÜZ

Yrd. Doç. Dr. Hülya BAYBEK

Yrd. Doç. Dr. Kemal Zeki ZORBAZ

Yrd. Doç. Dr. Mehmet MUTLU

Yrd. Doç. Dr. Menderes ÜNAL

Yrd. Doç. Dr. Metin DENIZ

Yrd. Doç. Dr. Nalan OKAN

Yrd. Doç. Dr. Nihat BAYAT

Yrd. Doç. Dr. Özlem TAGAY

Yrd. Doç. Dr. Sedat BALYEMEZ

Yrd. Doç. Dr. Seçil Eda KARTAL

Yrd. Doç. Dr. Semra KIRANLI GÜNGÖR

Yrd. Doç. Dr. Sinem TARHAN

Yrd. Doç. Dr. Şaban ÇETiN

Yrd. Doç. Dr. Taner BOZKUŞ

Yrd. Doç. Dr. Tekin ÇELIKKAYA

Yrd. Doç. Dr. Uğur DOĞAN

Yrd. Doç. Dr. Yakup DOĞAN

Yrd. Doç. Dr. Yılmaz KARA

Yrd. Doç. Dr. Yüksel GÜNDÜZ
Bartın Üniversitesi

Gazi Üniversitesi

İstanbul Sabahattin Zaim Üniversitesi

Nevşehir Hacı Bektaş Veli Üniversitesi

Muğla Sıtkı Koçman Üniversitesi

Akdeniz Üniversitesi

Nevşehir Üniversitesi

Muğla Sıtkı Koçman Üniversitesi

Mustafa Kemal Üniversitesi

Niğde Üniversitesi

Kırşehir Ahi Evran Üniversitesi

Bartın Üniversitesi

Niğde Üniversitesi

Akdeniz Üniversitesi

Mehmet Akif Ersoy Üniversitesi

Bartın Üniversitesi

Bartın Üniversitesi

Eskişehir Osmangazi Üniversitesi

Bartın Üniversitesi

Gazi Üniversitesi

Bartın Üniversitesi

Ahi Evran Üniversitesi

Muğla Sıtkı Koçman Üniversitesi

Kilis 7 Aralık Üniversitesi

Bartın Üniversitesi

Artvin Çoruh Üniversitesi 
Prof. Dr. Firdevs GÜNEŞ

Eğitim ve Zihinsel Değişim

Education and Mental Change

$1-20$

Doi: 10.14686/BUEFAD.2015111011

Yrd. Doç. Dr. Hicran ÇETiN GÜNDÜZ - Yrd. Doç. Dr. Sinem TARHAN - Zeynep KILIÇ Toplumsal Cinsiyete Dayalı Meslek Seçimlerine Yönelik Tutum Ölçeği Geçerlik ve Güvenirlik Çalışması Attitude Towards Gender-Based Career Choices Scale Validity and Relability Study

Doi: 10.14686/BUEFAD.2015111012

Doç. Dr. Fatma Ebru IKiz - Arş. Gör. Esra ASICI - Arş. Gör. Mustafa SAVCI - Arş. Gör. Canan YÖRÜKK Problemli internet Kullanımı ile Üniversite Yaşamına Uyum ilişkisi

Relations between Problematic Internet Usage and Adaptation to College Life

Doi: 10.14686/BUEFAD.2015111013

Arş. Gör. Zakir ELÇiçEK - Arş. Gör. İsmail KinAY - Prof. Dr. Behçet ORAL

Öğretmen Adaylarının Sınıf Yönetimi Yeterlik Ölçeğinin Geliştirilmesi: Geçerlik ve Güvenirlik Çalışması

Developing Teacher Candidates' Classroom Management Competency Scale: Validity and Reliability Study

Doi: 10.14686/BUEFAD.2015111014

$51-63$

Doç. Dr. Fahri TEMizYÜREK - Okt. Nihan Aylin ÜNLÜ

Dil Öğretiminde Teknolojinin Materyal Olarak Kullanımına Bir Örnek: "Flipped Classroom”

The Use of Technology in Language Teaching Material as an Example: "Flipped Classroom"

$64-72$

Doi: 10.14686/BUEFAD.2015111015

Doç. Dr. Gizem SAYGILI - Öğr. Gör. Halit KIRIKTAŞ - Arş. Gör. Hüseyin Talha GÜLSOY

Bazı Değişkenlere Göre Öğretmenlerin Empatik Eğilim Düzeyleri

The Level of Empathic Tendencies of Teachers According to Different Varibles

Doi: 10.14686/BUEFAD.2015111016

Doç. Dr. Hülya GÜR - Arş. Gör. Mevhibe KOBAK DEMiR

7. Sınıf Matematik Ders Kitapları Cebir Kazanımlarının Ön Örgütleyiciler Açııından İncelenmesi

The Investigation of the Algebra Learning Outcomes in 7. Grade Mathematics Textbooks in Terms of Advance

Organizers

$83-100$

Doi: 10.14686/BUEFAD.2015111017

Yrd. Doç. Dr. Şakir SERBES - Yrd. Doç. Dr. Cevdet CENGiZ

Sınıf Öğretmeni ve Beden Eğitimi Öğretmeni Adaylarının Tercih Ettikleri Öğretim Stilleri ve Stillere ilişkin Değer Algıları

Pre-Service Classroom and Physical Education Teachers' Teaching Styles Preferences and Perceptions of Teaching Styles

$101-114$

Doi: 10.14686/BUEFAD.2015111018

Yrd. Doç. Dr. Demet GiRGiN

Bireysel Çalgı Dersi Tükenmişlik Öıçeği Geliştirme Çalışması: Geçerlik ve Güvenirlik Analizi

Developing a Burnout Scale for Individual Instrument Courses: Validity and Reliability Analyses

$115-126$

Doi: 10.14686/BUEFAD.2015111019

Doç. Dr. Muamber YILMAZ - Dr. Hüseyin ÖZÇAKMAK

Öğretmen Adaylarının Öğretmenlik Uygulaması Dersleriyle Ilgili Görüşlerinin Değerlendirilmesi

Assessment of Prospective Teachers' Views on Teaching Practice Courses

$127-136$

Doi: 10.14686/BUEFAD.2015111020

Yrd. Doç. Dr. Erdal DEMiR

Ortaokul ve Liselerde Görev Yapan Branş Öğretmenlerinin Kişilik Özelliklerinin Değerlendirilmesi Assessment of Personality Traits of Branch Teachers Working in Secondary Schools and High Schools Doi: 10.14686/BUEFAD.2016111021 


\section{IÇiNDEKILER / CONTENTS}

Arş. Gör. Mustafa FiDAN

Akademisyenlerin Sınıflarında Örgütsel Değer Yönetimi Düzeyleri ve Öğretim Sürecinde İnovatif Uygulamaları

Organizational Value Management Levels in Classroom and Innovative Practices in Teaching Processes of Academics

Doi: 10.14686/BUEFAD.2015111022

Yrd. Doç. Dr. Nuray MAMUR - Prof. Dr. Vedat ÖZSOY

Görsel Sanatlar Eğitiminde Portfolyo Değerlendirme

Portfolio Assessment in Visual Art Education

Doi: 10.14686/BUEFAD.2015111023

Dr. Serap ERGiN - Prof. Dr. Musa SARI

4MAT Öğretim Yöntemi ve Sunuş Yoluyla Öğretim Yöntemine Göre Öğrencilerin Öğrenme Stillerinin Başarıya Etkisinin Araştırılması

The Research of the Effect of Students' Learning Styles on Their Achievements According to the 4MAT (4 Mode Application Techniques) and Expository Instruction Methods

Doi: 10.14686/BUEFAD.2015111024

\section{Doç. Dr. Ahmet AKIN - Oğuz AKKAYA}

Sosyal Yeterlik ve Sosyal Sonuç Beklentileri Ölçeğinin Türkçeye Uyarlanması

The Validity and Reliability Study for the Turkish Version of the Social Efficacy and Social Outcome Expectations Scale

Doi: 10.14686/BUEFAD.2015111025

\section{Yrd. Doç. Dr. Meriç ERASLAN}

Üniversite Spor Bölümü Öğrencilerinin Atılganlık ve Karar Verme Stillerinin Çeşitli Değişkenlere Göre incelenmesi

The Analysis of Impulsivity and the Decision Making Styles of Sports Students of the University According to Various Variables

Doi: 10.14686/BUEFAD.2015111026

\section{Çınar KAYA}

Attitude towards Seeking Professional Psychological Help in a Sample of Pre-service Teachers

Bir Öğretmen Adayı Örnekleminde Profesyonel Psikolojik Yardım Almaya ilişkin Tutum

Doi: 10.14686/BUEFAD.2015111027

\section{Yrd. Doç. Dr. Hasbi ASLAN}

Sosyalizasyonun Bir Bileşeni Olarak Sanat ve Sanat Eğitiminin Rasyonellik Görünümü

Rational View of the Arts and Arts Education as a Component of Socialization

Doi: 10.14686/BUEFAD.2015111028

Doç. Dr. Nurhayat ÇELEBi - Arş. Gör. Halim GÜNER - Veysel YILDIZ

Toksik Liderlik Ölçeğinin Geliştirilmesi

Developing Toxic Leadership Scale

Doi: 10.14686/BUEFAD.2015111056

Yrd. Doç. Dr. Erdal TAŞLIDERE - Doç. Dr. Ali ERYILMAZ

Assessment of Pre-Service Teachers' Misconceptions in Geometrical Optics via a Three-Tier Misconception

Öğretmen Adaylarının Geometrik Optik Konusundaki Kavram Yanılgılarının Üç-Aşamalı Kavram Yanılgısı Testi ile Değerlendirilmesi 


\begin{tabular}{|c|c|c|}
\hline $\begin{array}{r}\text { Bartın Üniversitesi } \\
\text { Eğitim Fakültesi Dergisi } \\
\text { ilt 4, Sayı 1, s. } 235 \text { - 248, Haziran } 2015 \\
\text { BARTIN - TÜRKIYE }\end{array}$ & ISSN: 1308-7177 & $\begin{array}{l}\text { Bartin University } \\
\text { Journal of Faculty of Education } \\
\text { Volume 4, Issue 1, p. } 235 \text { - 248, June } 2015 \\
\text { BARTIN - TURKEY }\end{array}$ \\
\hline
\end{tabular}

\title{
Sosyalizasyonun Bir Bileşeni Olarak Sanat ve Sanat Eğitiminin Rasyonellik Görünümü
}

Hasbi ASLAN, Yrd. Doç. Dr., Ondokuz Mayıs Üniversitesi, Eğitim Fakültesi, hasbi.aslan@omu.edu.tr

Öz: Bu çalışma, bireysel ve sosyal kültürün oluşumunda sanatın sosyalizasyon açısından önemini ortaya koymaktadır. Çağımızın sosyal ve kültürel ayırt edici özelliklerini okumaya çalıştığımızda bilim ve pedagoji, bireyin yetenekleri ve düşünsel yapısının sosyolojik açıdan belirleyici olduğunu dikkate alır. Toplumsal bütünlük açısından bireyin merkezde olduğu yapıda sosyalizasyon bir entegrasyon aracı olarak görülür. Toplumsal entegrasyonu kurgulayan sosyalizasyonun biçimlenmesi ise değerlerle mümkündür. Bireysel olarak kazanılan değerler kümesi sosyalizasyon süreci ile ilgili sonuçları kapsar. Değerlerin kültürel yansılarının öznel ve nesnel bakımdan değerlendirilmesi mümkün olduğunda ise sanat ve eğitimi, -iletişim biçimleri ve toplumsal yapının tüketim referansları bakımından- sosyalizasyonun bir bileşeni olarak incelenebilir. Kültürel kırılmalar, toplumsal yapı, medya ve temsil biçimleri, gündelik hayatın pratiklerini iletişim ve tüketim ekseninde sanat ve tasarım merkezli bir kültürel dönüşüm sürecine mahkûm etmiştir. Sanatın ve günlük yaşam tasarımları ilişkisinin öne çıktığı böylesi bir kültürel kırılma ve iletişim biçimlerinin oluşturduğu sosyal dönüşüm, büyük ölçüde pedagojik dönüşümlerle birlikte bireyin sosyalizasyon sürecine de etki etmektedir. Söz konusu bu etki sanatın aynı zamanda toplumsal gücünü ve birçok disiplin üzerindeki etkisini ve bağlayıcılığını da göstermektedir. Kitle kültürü ve yeni medya ile değişen ve gelişen sosyal iletişim yöntemleri ve uygulamaları, sanatın yoğun biçimde sosyalizasyon aracı olarak kullanıldığını göstermektedir.

Anahtar Kelimeler: Birey, sanat, sanat eğitimi, sosyalizasyon, toplumsal dönüşüm.

\section{Rational View of the Arts and Arts Education as a Component of Socialization}

\begin{abstract}
This study puts forward the importance of art in terms of its socialization in the formation of individual and social culture. When we try to read the distinctive of social and cultural features of our age, we see that science and pedagogy take into account that individual's talents and mental structure is decisive sociologically. In terms of social cohesion, in a structure where individual is at the center, socialization is seen as a tool for integration. Formalisation of socialization that makes up integration of social integration is possible through virtues. The cluster of virtues gained individually includes the effects related to the process of socialization. The cultural shadows of virtues can be studied in terms of contemporary consumption references of social pattern when it is possible to evaluate them subjectively and objectively. Within this context, the new culture, social pattern, media and its representation forms have confined the communication and daily routines to a process of cultural transformation centered in design and art along with communication. Such a social pattern and communication forms in which the relation of art and design stand out have some notable effects on pedagogical transformations. These effects show structural transformation statements for art and its teaching, foresights and expectations into question in addition to promoting the social strength of art and its effects on many disciplines. Social communication methods and applications that change and develop through mass culture and new media suggest that art is used asa tool for socialisation intensively.
\end{abstract}

Key Words: Individual, art, art education, socialization, social transformation. 


\section{Giriş}

Toplum ve kültürün ilgi alanları ve kaynakları her dönemde farklı bağlamlar ve değerlendirmelerle tanımlanır olmuştur. Buna göre, bütün zamanlarda topluma yön veren siyasal, sosyal ve kültürel ilgi kaynaklarının sonuçları geçmişten günümüze farklı bağlamlarla açıklanabilirken; sanat ve tasarım hiç olmadığı kadar günümüz kültürü ve bireyi açısından belirleyici ve etkin bir rol üstlenmeye başlamıştır. Sanat ve tasarımın informâl olarak endüstriyel, teknolojik ve iletişim bağlamlı kültürel etkileşimlerle- oluşturduğu bu etkinin, pedagojik doğrultuların uzağında kaldığı görülür olmasına karşın, sanatın oluşturduğu bağlamlar büyük ölçüde bireyin sosyalizasyonu ile ilgili neticeler ortaya koymaktadır. Sanat ve sosyalizasyona ilişkin tartışmaların dökümü açısından oldukça çelişkili olan bu durumun, -eğitim bilimi açısından değerlendirildiğinde-, sanat eğitimi programları ile sanat ve eğitiminin toplumsal algı referanslarından kaynaklandığı görülür. Buna rağmen, günümüz popüler kültür çağının özellikle tüketim anlayışlarında tasarım ve sanat olgusunun sosyalizasyonun önemli bir bileşeni olduğu anlaşılır. Bu nedenle, "sanatın eğitim müfredatlarında yer almasının sosyal bir olgu olduğu üzerinde durulabilir" (Freedman, 2003, 17). Kültür ve kültürlerarası etkileşim (sosyal antropoloji) açısından sanat ve tasarım birey ve toplum için güncel ve gelecekçi bir sosyalizasyon (Sosyalleşme-Toplumsallaşma) aracı olarak dikkati çeker. Bu yönüyle sanat entelektüel değişimlere yol açabilen dinamik bir karakteri ortaya koyar.

Toplum ve onu var eden en önemli olgu durumundaki kültür açısından birey, sosyalizasyon sürecinde bir bütünün parçası gibidir. Bireye verilen değer, sosyalizasyon açısından onu toplumsallaştırmaya yöneliktir. Topluma uyum, kültürü benimseme ve yaşatma doğrultusunda önem arz eden sosyalizasyon sürecinin güncel pedagojik ve toplumsal bir bağlantısı olarak sanat ve sanat eğitimini kültürel dönüşümler bağlamında incelemek gerekir. Belirli bir sistematiği ve kuralları olan sanat ve sanat eğitimi, gündelik yaşam tarzı ve tüketim anlayışlarında önem kazanmasına karşın, günümüz bireyi tasarım olgusu, estetik yargı ve bunların temelindeki sanat olgusu hakkında bilgi sahibi olmayı informâl yollarla gerçekleştirir. $\mathrm{Bu}$ özellikle bilginin temel öncelikleri, bilgi iletişim teknolojileri ve endüstriyel gelişmelerle ilişkilidir. Çünkü endüstri çağının ardından bilgi ve iletişim çağı büyük bir dönüşüm süreci ile görsel kültürün egemen olduğu bir çağa dönüşmüş durumdadır. Bu da, bilgi ve iletişim çağının temel kuramlarını etkilemekte ve sonuç olarak gündelik yaşamla ilişkili kavramlar büyük ölçüde dönüşüm geçirmektedir. Böylece oluşan tablo, toplumsal kırılmalar ve kültürel dönüşümler sonucunda sanat eğitimi ve sosyalizasyon ilişkisini kuvvetlendiren temel gerekçeleri olgunlaştırmaktadır. En kuvvetli gerekçelerden "sosyalizasyon, bireylerin kendi kültürünü ve toplumun içinde normlara uygun yaşamayı öğrendiği süreçtir. Bu süreçte dünyayı nasıl algılayacağımızı öğreniriz; kimliğimiz şekillenir; öteki insanlarla etkili iletişim kurmayı öğreniriz" (Newman, 2013, 74). Gelinen noktada sosyalizasyon süreci günlük yaşam deneyimleri, iletişim ve uyumla ilişkilidir. İnsanın farklı olanı keşfetme arzusu, bilimsel gelişmeler ve dönüşüm merakının çoğunlukla sanatın ve tasarımın muhtevası içinde açıklanabilir olması konumuz açısından önemlidir. Günlük yaşamın bireysel ve toplumsal gerektirmeleri sanat ve tasarım unsurlarının yoğunlaştığı alanları göstermekle birlikte buna imkân veren sanat ve eğitimine yönelik anlayışların da dönüşümüne referans olabilecek düzeydedir. Günlük deneyimlerimiz ve iletişim biçimlerimizin geleneksel bilinen kalıplarının hızla kırılarak dönüşüm geçirdiği etkileşimli, işlevsel ve toplumsal kalıpların işlendiği bir evredeyiz. Kültürel etkileşimlerin öne çıktığı bu evrede insani deneyimlerin ve ilişkilerinin üretim ve tüketim organizasyonunda gerekli olan bireysel yeterlik düzeyi birçok açıdan önemsenmesi gereken bir konudur. Örneğin bireyselliği öne çıkararak, devrimci bir rol üstlenen multimedya kültürel değişkenler üzerinde sosyolojik bir etki yaratmaktadır. İnsanın zihinsel ve deneysel yeterliklerinin öne çıktığı ve doğrudan kültürel formlar olarak belirlenen yöntemler -yaşam biçimleri ve tüketim anlayışları 
gibi- kültürün gelişmesine etki ederken, bireyin parçası olduğu kültürü geliştiren ve aktaran bir varlık olarak değerini öne çıkarmaktadır.

Sanatın toplumda bir düşünce varlığı olarak önemsenmesi ve sosyalizasyonunun toplumsal ve pedagojik gerektirmesi olarak güncellenmesi ülkemiz açısından önemlidir. Tasarımın kendisinin bir dönüşüm olgusu olarak algılanmasına ek olarak sanatın eleştirelliği, yaratıcılığı, üretim ve tüketim bağlamlarını, iletişim tasarımını, birlikte yaşama ve demokratik vatandaşlığı önermesi, eğitim programları ve toplumsal algının dönüşümü bağlamında ele alınabilir. Geçmişten günümüze kültürün oluşumunda ve yayılmasındaki önemi tartışılmaz olan sanat ve eğitiminin sosyalizasyona etki eden yapısı, güncel rasyonel gerekçelerle ifade edilebilir. Günümüz sosyal yapıları ve bireyi açısından sosyalizasyon sürecinde sanatın önemini kavramak ve bunu pedagojik dönüşümleri göz önünde bulundurarak gerçekleştirmek veya yapılandırmak dikkate alınabilir öncelikli bir gerekçedir.

Toplum ve birey ilişkisinin ortaya koyduğu sosyolojik imgelem bakımından sanat ve tasarım hayatımızı renklendiren, hareketlendiren, heyecan ve neşe katan en çağdaş ve en masum olgu olarak ele alınmıştır. Hatta spekülatif sanat kuramına göre, "sanatın duyumsal araçlar olan imge, simge ve ses dolayımıyla evrenin esasını açığa çıkardığı" (Shiner, 2010, 264) ileriye sürülür. Sanatın sosyal bir kurum olarak güçlenmesi ve kültürel bir olgu olarak kavramsallaşması doğrultusunda sosyalizasyon aracı olarak görülmesi günümüz toplumsal yapıları açısından önemli bir gerektirmedir. Sosyalizasyon aracı olarak sanat ve eğitiminin önemini kavramış kültürlere göre ülkemizdeki kültürel ve sosyal yapılanma, üretimden daha ziyade piyasa endeksli, tüketim formları ve edilgen yapısal bir görünüm içerir. Bu durum eğitime yönelik yapılanmalar açısından bir gösterge de olabilir. Varlığı büyük ölçüde sanat ve tasarım ilişkili üretim ve tüketim anlayışlarına bağlı olan günlük yaşam tasarımları, sanat ve sanat eğitimini sosyalizasyonun değeri olarak önemsememizi doğrulamaktadır.

\section{2. ÇALIŞMANIN AMACI}

Birey ve üyesi olduğu toplumsal yapıda sanatın önemi yadsınamaz. Sanatın kültürel olarak özümsenmesi ise sosyalizasyonu ile mümkün olabilir. Çünkü insan yaradılışının doğası gereği kendisini anlama ve sonrasında yaşadığı toplumu anlamlandırmaya, toplumsal kurumlarını ve bunlar arasındaki ilişkileri çözümlemeye ihtiyaç duyar. Çalışmamız, sanatın değişimin mimarı, dönüşümün sosyo-kültürel ajanı ve sanatın sosyalizasyonun bir bileşeni olarak görülmesini, yeni toplumsal ve kültürel kırılmaların eleştirisi üzerinden yaparak; sanatın genel olarak bütün bireyler için bir sosyalizasyon olanağı sağladığını rasyonel olarak ortaya koymayı amaçlamaktadır. Temel problem, bireyin kendisi ve toplumsal ilişkilerinde sanatın etkisini hatırlatmak ve sanat eğitiminin bireyin ve toplumun sosyalizasyonu için güncel ve gelecekçi referanslar önerdiğini ortaya çıkararak bunun için rasyonel doğrultular yaratabilmektir.

\section{YÖNTEM}

"Sosyalizasyonun Bir Bileşeni Olarak Sanat ve Sanat Eğitiminin Rasyonellik Görünümü" konulu bu çalışmada, belirli bir bilimsel birikimin verilerinin dikkate alındığı ve eğitim araştırma ve çalışmalarından sıkça tercih edilen bir araştırma metodu olan, literatür taramasına dayalı "kuramsal-analitik" bir inceleme, yöntem olarak belirlenmiştir (Büyüköztürk vd., 2008). Çalışmanın kapsamı gereği sosyalizasyonun yanı sıra dönüşüm ve sanat eğitimi ile ilişkili güncel kaynaklara değinilerek, belirlenen yöntem doğrultusunda sanat ve dönüşüm, toplumlardaki ve kültürdeki yeni pedagojik kırılmalarla karşılaştııılarak; sosyalizasyon için sanatın rolü vurgulanmıştır. 


\section{SOSYO-KÜLTÜREL EVRENDE SOSYALIZASYON VE DÖNÜŞÜM SÜRECI}

Bireyin yaşamında doğrudan etkili olan ve dinamik bir yapı içeren sosyalizasyon, hammaddesi dönüşüm olan bir kavramdır. "Yapısal-fonksiyonalist yaklaşım, her toplumun temel amacının kendi varlığını devam ettirmek olduğu hususunda bizleri uyarır. Bunun yolu ise toplumun, kendi istediği ve tasvip ettiği duygu, düşünce, arzu, istek ve hedeflere sahip bireyler yetiştirebilmedeki başarısından geçer. Bu bağlamda bir bakıma bu güçlü ve her yerde gözlemlenebilen sosyalizasyon süreci, toplumun ihtiyaçlarının, bireylerin ihtiyaçları haline dönüştürülmesi süreci olarak da tanımlanabilir" (Newman, 2013, 7). İnsanoğlunun kendisini birey olarak tanımlayıp, ait olduğu toplum içindeki sosyal fonksiyonlarının buna göre entegrasyonunu anlatan sosyalizasyon, süreç doğrultusunda adaptasyona ve dönüşüme karşılık gelen bir anlamı ifade eder. İnsanın bir varlık olarak önem kazanması sosyalizasyonun bir parçası olarak onun gerektirdiği kültürü içselleştirmesi ile doğru orantılıdır. Kültürün gerektirdiği edinimleri yaşam biçimi olarak içselleştirmek olan sosyalizasyon, birey ve dış dünya arasındaki iletişim ve etkileşimin kültürel olarak tanımlanmış homojen bir yapıyı ortaya koymaktadır. "Sosyalizasyon geniş anlamda sosyal roller için gerekli olan tutum ve davranışları öğrenmedir. Sosyallizasyon özellikle gelişmekte olan ülkeler için önemli bir temadır"(Mayer, 2004, xiii). "Insan gelişiminin en önemli temel taşı olan sosyalizasyon, insanların potansiyellerini geliştirdikleri ve kültürlerini öğrendikleri hayat boyu devam eden sosyal deneyim sürecidir" (Macionis, 2013, 113). Genel olarak sosyalizasyon süreci ve sözü edilen deneyim süreci "bireylerin, mensubu oldukları kültürün kurallarına ve beklentilerine uygun davranmayı öğrenmesi süreci" (Newman, 2013, 75) şeklindeki benzer kanaatler biçiminde ifade edilmektedir. Öğrenme ve davranış sonuçlarının belirlendiği bu süreçte zihinsel tepkimeler önemli rol üstlenmektedir. Arslantürk ve Amman, sosyalizasyon sürecinde zihniyetlerin, tutumların ve davranış kalıplarının şekillendiğinden söz etmektedir $(2013,369)$. "Sosyalizasyon bir öğrenme sürecidir. Sosyalize olan birey, uygun davranmayı öğrenme sürecini yaşıyor demektir" (Newman, 2013, 64). Destekleyici bir başka görüşe göre de sosyalizasyon, "kişinin grup normlarına uyması ve bunları öğrenmesini sağlayan süreçtir" (Arslantürk ve Amman, 2013, 162). Birey, konuşma, öğrenme ve iletişim kurma gibi kişiliğini anlamlandıracağı bütün yaşam biçimlerini ancak bu süreçte dönüştürebilir. Böylece, bireyin yaşamı boyunca süren "sosyalizasyon, kültürel bilgileri öğrenme ve içselleştirme sürecidir. Bu öğrenme süreci, hayatımız boyunca etkileşimde bulunduğumuz çok sayıda birey, grup, organizasyon ve kurumun etkisinde gerçekleşir. Bireyin sosyalleşmesinde etkili olan bütün bunlar sosyalizasyon ajanları olarak tanımlanır" (Newman, 2013, 64). Bireyin düşünme edinimi, algı frekansları ve yaşam biçimi büyük ölçüde zihinsel tepkimelerini belirleyen faktörler olarak belirtilir ve bütün bunlar sosyalizasyon aracıları ile anlam kazanabilir. "Insan beyninin zihinsel olarak gelişmesi, olgun grup üyelerine bağımlıdır" (Gauvain ve Perez, 2007, 590). Zihinsel bir tepkime ve zihinsel bir dönüşüm ve değişimin söz konusu olduğu bu süreçte, bireyin dış dünyaya verdiği yanıtlar veya tepkimeler bütünüyle sosyalizasyonun düzeyini belirlemektedir. "Sosyalizasyonun bireyler açısından en önemli çıktılarından biri de öz benlik algımızın gelişimidir" (Newman, 2013, 74). Zihinsel bir dönüşüm, yeni bir kimlik ve yeni bir kişiliğin oluşumunu ortaya koyan birey böylece toplumsal varlık olmanın ve toplumsal bütünleşmenin de gereğini yerine getirmiş olur. Görüldüğü gibi sosyalizasyon süreci doğrultusunda birey bir entegrasyon ve dönüşüm süreci içerisinde yer alır. Sosyalizasyonun bütünüyle tamamlanması bir anlamda dönüşümsel süreç bakımından anlam taşımaktadır. "Sosyalizasyon yalnızca çocukluk sürecince devem eden bir süreç değildir. Yetişkinler de her yeni durum karşısında yeni beklentileri, değerleri öğrenerek yeniden sosyalleşmeli, eskiler yenileri ile değiştirmelidir" (Newman, 2013, 74). Sürekli dönüşüm ve değişimin hâkim olduğu sosyalizasyon sürecinde birey, öz benliğini ve kişiliğini şekillendirirken, aynı zamanda kendisi için tasarlanan ve istenen toplumsal kalıpların neler olduğunu da öğrenmiş olmaktadır. "Bilişsel gelişim aşamasında çocukların, toplumun entelektüel yaşamına ayak uydurabilmeleri sosyalleşme süreci ile mümkündür. Sosyal etkileşim 
sürecinde çocuklar böylece kendi başlarına üretemeyecekleri kültürel uygulamaları gerçekleştirir" (Gauvain ve Perez, 2007, 588).

Sosyalizasyonun gerçekleşmesi birçok toplumsal kurumun entegrasyonuna bağlıdır. "Sosyalizasyon bir boşlukta gerçekleşmez. Etnik, ırksal ve sınıfsal kimliğiniz, cinsiyetiniz vb. faktörler sosyal kimliğinizin gelişimi açısından hayati önem arz eder" (Newman, 2013, 69). Birey bir yandan biyolojik olgunlaşma sürecini tamamlarken, aynı zamanda toplum normları ile bütünleşmektedir. "İnsanın toplum hayatı, aklın ve düşünme yeteneğinin eseri olup, sürekli bir değişim halindedir. Bu da insan şahsiteyinin sosyalleşme sürecinde oluşması demektir" (Arslantürk ve Amman, 2013, 161). Öz kimliğin oluşması ve sosyalizasyonun gerçekleşmesi sürecinde kurumsal olarak, kitle iletişim araçları, sosyal medya ve sanat eğitimi öne çıkarken, "sosyalizasyon ajanları kişiliğimizi, kendimizi algılayış ve ifade edişimizi, ilgilerimizi, zevklerimizi, duygularımızı, değerlerimizi, tutum ve davranışlarımızı etkilemektedir" (Newman, 2013, 64). Elbette bireysel kimliğimizi etkileyen unsurlar bunlarla sınırlanamaz; eğitim kurumları, dini kurumlar, medya/kitle iletişim araçları ve sanat gibi sosyal kurumlar da sosyal kimliğimizin şekillenmesinde önemli ölçüde etkilidir. Yeni dünyanın ve yaşam biçimlerinin dönüşen sanatsal potansiyelleri sanatı birey açısından önemli bir sosyalizasyon aracı konumuna getirmiştir. Teknoloji, estetik, kültür, iletişim teknolojileri, medya ve tüketim tercihleri bağlamsal olarak sanat ve sosyalizasyon ilişkisini artıran etkenler olarak dikkati çeker. Birbirleriyle daha çok temas eden bu kavramlar karşı karşıya olduğumuz dünyanın yeni estetik ve iletişim boyutlarındaki yaşam biçimlerinin sanatla olan bağlantılarını bütünüyle artırmıştır. Birbirleriyle bağlam oluşturan bu kavramlar birer medya kentlere dönüşen ortamlarda bireyin mutlak surette temasa geçtiği sosyalizasyon aracıları olarak görülebilir.

Zaman, mekân ve insan faktörlerinin bağlamsal ilişkileri sosyalizasyon sürecindeki dönüşüme yeni bir anlamlar yüklemektedir. Sosyalizasyonun bu bağlamlar doğrultusundaki dönüştürme süreci içerisindeki eylemlere, anlam katan birey öz eleştirel düşünme ve bunun doğrultusundaki katılım sürecine tabidir. "Değişimin, sosyolojik düşünmeyi teşvik ettiği gibi, sosyolojik düşünme de değişime sebep olabilir. Sistemin nasıl çalıştığı hakkında ne kadar çok bilirsek onu bir şekilde değiştirmeyi o kadar isteyebiliriz" (Macionis, 2013, 6). Sosyalizasyona etkisi açısından bireyin toplumsal dönüşümünde, düşünme hareketleri ile birlikte, kültürel sınırlılıkların ya da ölçütlerin boyutları ve yapıları da dönüşüm geçirmektedir. Dünyamızın teknoloji ve iletişim biçimleri ile küresel bir köye dönüştüğü şeklindeki görüşlerin temeli de bu düşünceye dayanır. Bununla birlikte kültürel paylaşımlar ve kültürel dönüşümler söz konusu olmuştur. İçinde bulunduğumuz enformasyon yüzyılı kültürel dönüşümün yönünün yeninden belirlendiği bir profili ortaya koymaktadır.

Sosyalizasyon sürecinin işlevsel sonuçlarını ortaya koyan aşağıdaki tabloda da görüleceği üzere (Decenzo \& Robbins, 2012), sürecin tam merkezinde yer alan dönüşüm, sosyalizasyon sürecine entelektüel ve fonksiyonel bir karakter kazandırmaktadır. Burada, sosyalizasyon sürecinin sonuçları öncelikle dönüşüm kavramının etkinliğine doğrudan bağlı olarak gelişmekte ve değer kazanmaktadır.

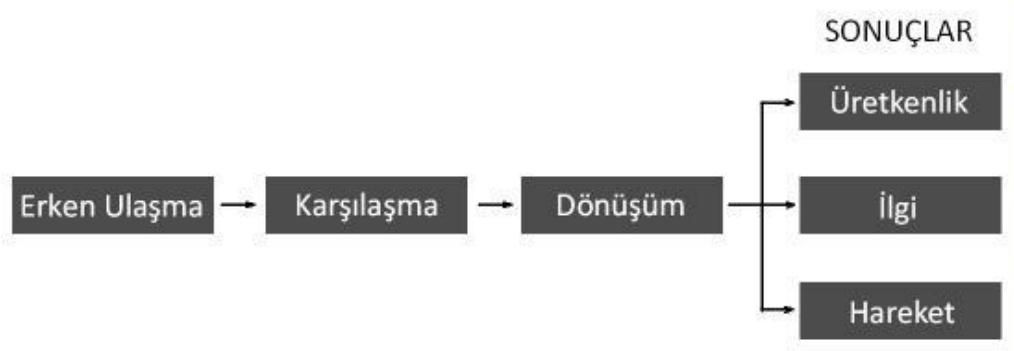

Şekil 1: Sosyalizasyon Süreci 
Dönüşüm kavramını sosyalizasyon sürecinin temel unsuru olarak kuvvetlendiren nedenlerin öncelikle birey tarafından ortaya konacak olan öz-eleştirel yaklaşım modeli ve entegrasyon düzeyi ile ilişkili olduğunun bilinmesi daha doğru alacaktır. Sosyalizasyon için dönüşüm sürecini tamamlamak bireyin zihinsel ve sosyal düzeyine ek olarak kabullenme duygusu ile de doğru orantılıdır. Zihinsel ve sosyal açıdan bireyi destekleyen sanat eğitimi ile kazanılan değerler sosyalizasyon için dönüşüm süreçlerine etki edebilecek önemli bir referans olarak gösterilebilir.

\section{TOPLUMSAL VE KÜLTÜREL KIRILMALARLA DÖNÜŞÜM EYLEMININ SOSYAL VE}

\section{ÖZNEL DÜNYAYI BÜTÜNLEYICI YAPISI}

Daha henüz başında olduğumuz 21. yüzyılı tanımlayabilecek en gerçekçi ifade modellerinden ikisi kuşkusuz 'değişim' ve 'dönüşüm' kavramları olacaktır. Yaşam biçimlerinin öne çıkan ve değişen yeni yapıları ve kalıpları, toplumsal kuralları geçmişteki örneklerine göre oldukça değiştirmiştir. Yeni yüzyılın ilk çeyreği bile henüz dolmadan günümüze ait yeni toplumsal yapı, öncelikle medya ve iletişim teknolojileri ile açıklanabilecek doğrultuda görsel kültür ve estetik tüketimin egemen olduğu anlayışlara ve kültürel kırılmalar için yeni tanımlamalara açıklık getirecek düzeydedir. Böylesine bir kırılmanın kültürel boyutları açısından Türk Alfabesine eklenen yeni harfler ile görsel iletişimin etkileri örnek olarak gösterilebilir. Bu değişimi olağan kılan etkiler, uluslararası boyutları kapsayan bir kültürel gelişme, sosyalleşme ve etkileşim anlayışlarından kaynaklanmaktadır. Böylece günlük iletişim biçimlerinin ve hatta dillerinin dönüşmesi bağlamında genel kültürün boyutlarının, yaşam biçimlerinin toplumsal anlamda dönüşmesi söz konusu olmuştur. Sosyal değişme, çevre ve nüfus baskısı, kültürel ve teknolojik yenilikler, teknoloji ve kültürün yayılması gibi nedenlere bağlanmaktadır. Değişim konusunda çalışan sosyologlara göre kurumsal dönüşümler, zaman içinde meydana gelen çok çeşitli toplumsal güçlerin etkisiyle gerçekleşmektedir: Bunlar arasında çevre ve nüfus baskısı, kültürel icatlar, teknolojik ve kültürel yayılma sayılabilir (Newman, 2013, 233-236).

Toplumsal ve kültürel kırılmaların ana maddesi insandır. Böylelikle mevcut durumunu sorgulayan ve dönüşümü talep eden bireyin kendisidir. "Insanın kendi konumundan hareketle yenilikçi çabalar içine girmesi gerçekte yeni ihtiyaçlar, inançlar, değerler ve düşüncelere yol açacak önemli bir başlangıçtır" (Doğan, 2009, 343). Kültürel ve toplumsal kırılmaları siyasal olaylardan bağımsız olarak ifade edecek olursak, özellikle ekonomideki büyüme ve gelişme, istenen değişmeleri ifade eden ilerleme ve gelişme toplumsal ve kültürel kırılmalarda rol oynayan önemli birer faktördür. Bu faktörler çoğu zaman toplumsal ve kültürel kırılmaların hızını ve yönünü de belirleyebilmektedir. Kültür unsurlarını ifade eden normlar ve değerlerin karşı karşıya kaldığı böylesi bir kırılma sürecini ancak bireyin daha çok bilgi edinme, etkileşim, deneyim ve iletişim arzuları belirlemektedir. Ancak toplumsal değişimin genel faktörleri arasında sayılan düşünce ve teknolojik faktörlerin etkisini de unutmamak gerekir.

Toplumsal ve kültürel kırılmaları dönüşüm kavramı ile ele almaya çalıştığımız bu bölümde sözü edilen kırılmaların özellikle sosyoloji dilindeki değişme ile de açıklayabiliriz. Toplum yapı itibari ile hareketli bir organizma gibi görülür. Dolayısıyla toplumu oluşturan sistemler aynı hareketlilik ölçüsünde büyüme, gelişme ve değişme ile yüz yüze kalmaktadır. Buradaki değişim mevut durumun ele alındığı bir başkalaşım süreci şeklinde anlaşılmalıdır. "Toplumsal değişme, toplumsal yapının ve onu oluşturan toplumsal ilişkiler ağının ve bu ilişkileri belirleyen toplumsal kurumların değişmesidir. Toplumsal değişmeyi kültürdeki değişmelerden ayırmak zordur. Bu yüzden toplumsal değişmeleri sosyo-kültürel değişmeler olarak belirlemek gerekir" (Tezcan, 1993, 211). Bu bakımdan toplumun kültürel değerleri ve toplumsal iletişim biçimleri ile ilişkili olarak sanat ve tasarım, toplumsal değişimin iletişim ihtiyacını karşılayan ve yönlendiren bir güç olarak görülebilir. Günümüz modern toplumları için öngörülen yaratıcı ve eleştirellik değerleri bakımından sanatın kültürel etkilerini öne çıkarmak 
durumundayız. Çünkü sanat ve tasarım birey ve toplum için daima yenilikçi unsurları sunabilen bir dönüşüm aracıdır. Sanatın buradaki gücü ve bağımsızlığı onun denetlenemeyecek kadar bağımsız olmasından da kaynaklanır. Onun daimi hedefi bağımsızlık, özgürlük, demokrasiden yana bir dönüşümdür. Sanatın sağladığı bu dönüşüm çoğu zaman planlı bir dönüşüm olmayabilir. Buradaki planlı dönüşümler ancak eğitimin görevi olabilir. Gelecekçi bir toplumda yapılandırıldığı ölçüde sanat ve tasarım, toplumlardaki kültürel kırılmaların öncüsü alabilir. Bu durum, sanatın özgürleştirici ve yenilikçi işlevlerinin bir görünümüdür. Sanat eğitimi böylece özgürleştirici ve eleştirel birey öngörüsüyle toplumları dönüşüme hazırlayabilir.

Günümüzde belirli kültürel kalıpların birbirleri ile etkileşimleri sonucunda yeni kültürel kırımaların ortaya çıktığını ve bu kırılmaların birbirleri ile etkileşim içinde olduklarını, daha ziyade birbirlerinden etkilendiklerini veya birbirlerini takip eden süreçlerden etkilendiklerini görüyoruz. Sözünü ettiğimiz kırılmaların başlıca aktörleri olarak teknolojik faktörleri, siyasal, endüstriyel ve sosyal faktörleri öncelikli olarak belirtmek mümkündür. Bu faktörlere ek olarak sanatın ve sanat eğitimini toplumsal ve bireysel değişim aracı olarak belirtmek yanlış olmayacaktır. Bu bakımdan yaşadığımız dönemi tanımlamak açısından dönüşüm kavramı oldukça yerindedir. Böylece dönüşüm toplumsal ve kültürel kırılmaların da belirleyicisi olmaktadır. Bu süreç, geleneksel olarak tanımlanabilen birçok toplumsal ve kültürel kodları hızla dönüşüme uğratmaktadır. Yeni kültürel ve toplumsal belirleyiciler küresel anlamda oluşturduğu düzende; geleneksel kültürel farklılıkları ortadan kaldıran, çoklu kültürü ve bireyselliği destekleyen yapıları yaşam standartları ve kalıpları olarak dayatmaya çalışmaktadır. Günümüzün sosyalizasyon anlayışlarının ve kalıplarının, popüler kültürün veya kitle kültürünün sosyal medya ile oluşturduğu tasarım ve estetik bütünselliğindeki yeni iletişim biçimleri ve tüketim olgularından büyük ölçüde etkilendiği ve dönüştüğü görülmektedir.

\section{SANAT EĞitiminin SOSYALIZASYON KARAKTERININ RASYONELLEŞMESi VE KURAMSAL OLARAK TEMELLENDIRILIŞi}

İnsan yaşamının her dönemi pedagojik olarak belirlenmiş bir takım süreçler ile ilişkili olsa da, bu süreçlerin sanatla olan bağlamları ve etkileşimleri sosyal bir olgu ve sosyal bir oluşumdur. Sanat her dönemde insani meziyetlerin en değerli göstergelerinden biri olagelmiştir. "Sanat sosyolojik bir karakterdir. Bilgi ve kültürel ürünlerin sosyolojik bir karakteri vardır. Çeşitli sanat eserleri, dilin ve toplumsal bağlamlar arasındaki ilişkileri tanımlamak amacıyla kullanılır olmuştur. Bu anlamda sanat eserlerinin üretimini oluşturan koşullar araştırıldığında, genel olarak bütün sanatsal çalışmaların toplumsal vurguları görülür" (Becker, 1989, 41). Sanata verilen bu değer onun bireysel, sosyal, kültürel ve zihinsel yapılar doğrultularında medeniyetlere olan genel katkısından kaynaklanır. Bu doğrultuda sanat birey ve toplum için bir kategori olarak gösterilebilirken bu durum aynı zamanda onun -her dönem içinde- gerekli ölçüde toplumsallaştırılamaması ve içselleştirilememesi gibi sorunları da ortaya koymuştur. "Toplumsal ve evrensel yönleri ile insanları birbirine kaynaştıran bir özelliğe sahip olan sanat ve kültür toplumsal bir değer olarak tarih boyunca insan topluluklarının olduğu her yerde var olmuştur" (Yılmaz, 2009, 43). Birey ve toplum ilişkisinde sosyal ve kültürel bir olgu olarak sanatın varlığı çok çeşitli konu başlıkları altında bir değerlendirme konusu yapılabilir. "Nietzsche de Schopenhauer'le birlikte, sanatın, bilimin ve felsefenin, yanılsamanın biçimleri olduğunu söyler. Sanat aracılığı ile yeniden yorumlanarak yeni baştan kurulan ve bir işlev kazandırılan yaşam, varlığın anlamsız bir akışından, sürüklenişinden anlamlı bir bütünlüğe ve düzenli bir dünyaya dönüşür" (Bozkurt, 2013, 175). İnsanın ontolojik olarak bütün özellikleri ile ilgilenebilen sanatın işlevi, geçmişi ve geleceği kapsayabilen değerlerle örtüşebilir. "Tıpkı konuşma gibi bir iletişim aracı olan sanat, bu niteliğiyle ilerlemenin, başka bir deyişle insanlığın mükemmelliğe doğru yürüyüşünün de bir aracıdır" (Tolstoy, 2013, 173). Bir takım yetenekler, beceriler ve değerlerin bireysel etkilerinin tartışıldığı sosyalizasyon sürecinin bir görünümü 
olarak birey ve sanat ilişkisi, toplum ve sanat ilişkisi ya da sanatsal sosyalizasyon, bireylerin ve toplumların daha çok sanatla iç içe olmalarını ve günümüzün sanat, medya ve teknoloji üçgeninde gelişen günlük yaşam modellerini dönüştüren bireyler olarak farkındalıklarının ve deneylerinin geliştirilmesi ile ilgili bir konu olarak ele alınabilir. Özellikle son yirmi yılda sanat, klasik ve modern bakış açılarını dönüştürerek, günümüze özgü daha medyatik ve çok daha günlük yaşama bağlı olan biçimlerde var olma eğilimi göstermektedir. Örneğin, günümüz açısından görsel kültür hiç olmadığı kadar -kamusal anlamda- informal olarak bir müfredat halinde gelişebilmiştir. Büyük ölçüde teknoloji ve iletişim biçimleri ile bağlantılı olan bu durum sanat eğitiminin ilgilenmesi gereken; belki de yeni bir Rönesans olarak da tanımlanabilecek düzeydedir. "Toplum ve sanat arasındaki ilişkiye yönelik çeşitli teoriler vardır. Ancak bunların geneli sanatın toplumsal doğasına ilişkindir" Foster, 1989, 4). Sanatın kitle kültüründen güç aldığını iddia ettiğimizde onun zamana, mekâna ve bu doğrultuda yaşam biçimlerine göre dönüşebileceğini öngörmek de sosyal antropolojik açıdan mümkün olabilecektir. "Bilginin evrimi nasıl gerçekleşiyorsa, yani daha gerçek ve daha gerekli bilgi, yanlış ve gereksiz bilgiyi nasıl dışlıyor ve onun yerini alıyorsa, duyguların evrimi de sanat yoluyla gerçekleşiyor" (Tolstoy, 2013, 173). Bir bakıma insanlığın kültürel evrimi içinde daha öncelikli ve gerekli görülen değerler ve bilgiler sanat yoluyla yücelmektedir.

Günümüzün sosyalizasyon faktörlerinin en etkilisi durumundaki kitle iletişim araçlarının davranış örüntüleri ve tutumlarımızın belirlenmesindeki etkisi düşünüldüğünde, sanat ve tasarımla ilgili sosyalizasyon değerlendirmeleri, teknik ve sosyal bağlamları ifade etmek için açıklayıcı olabilir. Kitle iletişim araçlarını bütünüyle etkileyen tasarım olgusu, dönüşümsel olarak sürekli yenilikçi bir ekonomi ve dinamik bir tüketim anlayışı yaratmıştır. Bu anlayış genel olarak sosyolojinin çalışma alanları ile ifade edilmektedir. "Medya ya da diğer adıyla kitle iletişim araçları önemli bir kurumsal sosyalizasyon araçlarıdır. Gazeteler, dergiler, televizyon, radyo, filmler ve internet siteleri gerçekliğin doğasına ilişkin neredeyse sınırsız derecede mesajlar iletmektedir" (Newman, 2013, 73). Merger (2005)'den aktaran Newman, kitle iletişim araçlarının, neyin önemli ya da önemsiz olduğunu belirleyen sosyal, ekonomik ve siyasi enformasyona yön veren kapı bekçileri gibi olduklarını belirtir $(2013,73)$. Günümüzde, iletişim teknolojilerine artan sosyo-kültürel ilginin neticesinde, insanın kişiliğini oluşturması ve sosyalleşmesinin pedagojik kodları yeniden önem kazanmaya başlamıştır. Bu hareket sosyolojik düşüncenin gelişmesinden ileriye gelmektedir. "Sosyolojik düşüncenin en önemli yararı 'bireyin çevreye ait problemlerini' toplumsal yapıya indirgemesi ve bu yapıdan kaynaklanan problemlerden ayırt etmesidir" (Doğan, 2009, 9). Bu itibarla sosyolojik düşünce kültürel anlam olarak sanatla ilişkili olarak bir form kazanabilir. "Sosyolojik düşünce sosyal bilimleri gerek alan, gerekse uğraşanlar açısından etkilemektedir. Bu itibarla tarih, biyografi ve bunların toplum içindeki kesişme noktasını dikkate almayan hiçbir toplumsal inceleme fikri çerçevesini tamamlamış sayılmaz" (Doğan, 2009, 9). Sanat, sosyolojik bir bilgi ve kültür dünyası oluşturur. Bu bakımdan, "sanat yapıtının ortaya koyduğu dünya, belli bir açıdan 'toplum' diye de adlandırılabilir" (Dellaloğlu, 2007, 8). Bu ortamdaki, "sosyolojik bilgi insanı, yaşadığı toplumun bir parçası olarak insana ait tüm ürünleri (sorunları, bilgi, düşünce ve projeleri) ait olduğu topluma indirgeyerek açıklama girişimidir" (Doğan, 2009; 9). Bireyin sosyalizasyonu sosyolojik bilginin kültürel olarak çözümlenmesi ve aktarılması ile mümkün olabilmektedir. "Sosyalizasyon kültürün zaman içerisinde, yeni kuşaklara aktarılmasının başlıca kanalıdır" (Giddens, 2005, 25). Sosyalleşme ve sosyalizasyon bireyin kültürel olgu ve olaylara karşı öz eleştirel yorumları doğrultusundaki dönüşümünü gözlemlememize imkân vermektedir. Çünkü "toplumsallaşma birey açısından 'başkası düşüncesi' çevresinde gelişir" (Doğan, 2009, 86). Buna göre sokak, diğerleri düşüncesinin birey özelinde aileden sonra ilk çözümlendiği ortamdır. Dikkat edileceği gibi, sosyalizasyon sürecinin en önemli fikri, düşüncenin dönüşümü olarak önem kazanmaktadır. Bütün bireyler düşünsel olarak parçası oldukları kültürün birer üreticisi ve tüketicisi durumundadır. Günlük yaşam içinde işlevsel ve bir o kadar etkili ve tartışılır hale 
gelen tasarım, dönüşüm, sanatçı ve eseri, kültürel yapılar için önemli birer gösterge durumundadır. Düşünsel açıdan, sanatın bir anlatım ve anlam aracı olduğu düşünüldüğünde birey ve toplum arasındaki ilişkide bir anlam ve uyum aramak mümkün olabilmektedir. Bilim ve onun sonuçlarına göre elde edilen teknoloji kadar toplum için değerli ve etkili olan sanat, birey ve üyesi oldukları toplumlar için bilim ve teknoloji ölçüsünde bir kaynaktır. "Bilim ve sanatta yaratıcılık eşit değerde kabul edilmektedir" (Buyurgan, 2008, 9). Bu doğrultuda bireyin ve toplumun hayatını anlamlandıran sanat, sanat eğitimi, tasarım ve yaratıcılık süreci, öncelikle bireysel olarak içselleştirildiği ve sosyalizasyonu sağladığı ölçüde anlam ve değer kazanabilir. "Dünyanın birçok yerinde siyaset, ekonomi, kitle iletişim, eğitim alanları ile birlikte teknoloji alanında ilerlemeler hızla gerçekleşmektedir. Hassas dengeler içinde, sanatın rolü ve insan hayatındaki etkisi yaygın bir şekilde hissedilmeye başlanmıştır. Sanat, insanları birbirine yaklaştırma gücü, farklılıkları anlayışla karşılama, bireyselliklerin zenginliği gibi unsurlar için gereklidir. Sanatın anlaşılması için sanat eğitimi çağdaş insan hayatında yer almak zorundadır. Sahip olduğumuz zengin tarihi, sanatsal ve kültürel değerlerin farkına varmak, kendi özgün sanatını yaratmak sanatı doğru okumakla mümkündür" (Erbay, 2013). Bireyin ihtiyaçlarını beceri yoluyla karşılamasına temel oluşturan sanat ve sanat eğitiminin bu yönü onun sosyoloji ve sosyalizasyon kavramları ile ilişkili olduğunu gösterir. Bu yönüyle sanat ve sanat eğitimi bireyin duyusal ve bilişsel algı dayanaklarına da temel oluşturmaktadır. Sanat eğitimine yönelik böylesine bir bireyci ve toplumcu bir yaklaşımın temelinde bireyin kendisini keşfetmesi ve içinde yaşadığı toplumun etkin bir parçası olması durumu ile karşılaşmaktayız. O halde sanat eğitiminin amacı her şeyden önce birey ve topluma ulaşmaktır. "Çağdaş sanat eğitimi, temelde sanatsal etkinlikler yoluyla bireylerin ve toplumun içinde yaşadıkları çevreye duyarlı olmalarını sağlamaya, çevresi ile yararlı bir etkileşim içine girebilmelerine imkân vermeye yönelik düşüncededir" (Buyurgan, 2008, 10). Dolayısıyla sanat eğitimi toplumcu bir süreçtir. Çünkü sanatın amacı sanatsala ulaşmak iken böyle bir şey sanat eğitimi için mümkün değildir. Bu nedenle sanat eğitimi bağlamında sosyalizasyon mümkündür ve ülkemiz açısından işlenmesi gereken gerekçeleri tespit edilebilir. Çağdaş sanat kuramlarının ortaya çıkı̧ nedenlerinin, birey ve toplumsallaşma gereklerinden kaynaklandıkları düşünüldüğünde dikkat çekmeye çalıştığımız konunun kapsamı daha net olarak algılanacaktır.

Sanat yoluyla sosyalizasyon veya sanatın sosyalizasyonu farklı anlamlara gelse de konumuz gereği biz çalışmamız kapsamında her iki olgu ile de ilgilenmek durumundayız. Toplumsal bir kurum olan sanatın sosyalizasyonu yani toplumsallaşması mümkün olmayan bir durum olarak görülebilir. Bu doğal olarak da sanatın özüne oldukça uzaktır. Çünkü sanat özgürdür. Bu yolla sanatın topluma ayak uydurması, toplumun gelenek ve göreneklerine uygun hale getirilmesi her durumda mümkün olmayabilir. Sanatın sosyalizasyonu, bireylerin sosyalizasyon aracıları yoluyla sanata katılmaları anlamını taşımaktadır. Ancak sanat ve sanat eğitimi ile sosyalizasyon daha gerçekçi ve gelecekçi bir bakış olarak görülmekle birlikte bu ülkemiz açısından dikkate alınması gereken özel bir durumdur.

Amacımız, birey ve toplum yararına sanat ve eğitiminin sosyalizasyonun bir parçası bağlamında, pedagojik formasyon olarak ele alınmasını gerçekleştirmek ve bunun için gerekli doğrultuları tanımlayarak temellendirmektir. Sanat öngörülemez evreni ve aykırılıklarıyla insanlık tarihindeki ayrıcalıklı yerini daima korumuştur. Özellikle ülkemizde sanat, sanat eseri, sanatçı, birey ve toplum ilişkisinde sanatın sosyal fonksiyonları günümüz toplumsal gerçekliğinde yeniden ele alınması gereken bir konudur. Sanat ve toplum bağlamında bir sosyalizasyon ilişkisinden söz ederken zaman, mekân ve kültür bileşenlerini bağlamsal olarak ele almak gerekir. Bu ilişki sanatı var eden olguların/kavramların bütün zamanlarda olduğu gibi günümüze ait toplumsal ilişkilere ve birey iletişimine olan etkilerini açıklamak için önemlidir. Sanatın sosyal sistemlerle böylesine kurduğu ilişki, pek çok kez sosyal sistemlerden bağımsız bir 
şekilde de ele alındığı olmuştur. Ortaya konulan sanat eserinin toplumsal ilişkisi ise o anlık tasarımı ile açıklana gelmiştir. Bu bağlamda toplumsal dönüşümün gerçekleştiği hassas dönemlerde, sanat eserinin toplumsal ilişkisinin daha kolay teşhis edilebildiği dönemler olarak belirtilebilir. "Kitlelerin pratikteki yaşam faaliyetlerini imgeleştiren sanatın, topluluğun her üyesinin anladığı ve ulaştığı bir dili konuştuğu, dolayısıyla, sanatçının uyumlu ve toplumla bütünleşmiş bir şahsiyeti olduğu söylenebilir" (Ulusoy, 1997, 11). Sanatın kültürel alanda geliştirdiği ve sürdürdüğü sosyolojik ilişki, bireyin toplumsallaşma süreci açısından önemlidir. Farklıığı, uyumsuzluğu, estetiği, deneyimi, iletişimi ve medyayı yöneten sanatın kültürel alanı, günlük hayatın pek çok anında hüküm sürmektedir. Yenilikçi sanat sosyal düzenin de belirleyicisi olurken, pedagojik sahaya da etki etmektedir. Bugün özellikle Batı'da sanatın pedagojik sahasında karşılaştığımız -yeni sanat eğitimi yöntemleri olarak- görsel kültür, görsel okuryazarlık, disiplinler arası sanat eğitimi gibi seçkin ve popüler yaklaşımlar hem sanat eğitiminin hem de genel eğitim ve öğretim programlarını etkileyebilecek kadar önemsenen toplumsal içerikli yaratıcı uygulamalardır. Bireyin günlük yaşamdaki pratik faaliyetlerini anlatan sanatın günümüz toplumlarının üzerinde ortak dili konuştukları, homojen etkide evrensel bir sosyal dönüşüm aracı durumundadır. Endüstriyel ve kültürel gelişmelerin güncel paradigmaları, bütün disiplinleri birbirleri ile etkileşime mecbur kılabilen ve birbirlerinden bağımsız düşünülemeyeceği öngörüsünü pekiştirmeye yöneliktir. Toplumun sanat ve eğitimi doğrultusundaki sosyalizasyonuna bağlı olarak yenilikçi sanat eğitimi programlarından söz edilebilmektedir. Batı'daki sanat eğitimi programlarında dikkati çeken görsel kültür, görsel okuryazarlık, görsel iletişim tasarımı, medya ve sanat ve de disiplin temelli sanat eğitimi gibi programlar sanat eğitiminin yenilikçi ve gelecekçi yüzünü tanımlayabilecek niteliktedir. Özellikle, "her şeyi kapsayan görsel kültürün ortaya çıkması, sosyal etkileşim ve kültürel kimlik temelinde politik söylemin doğasını dönüştürmüştür. Görsel kültür aynı zamanda görsel sanatlar alanını da genişletmiştir" (Freedman, 2003, 17). Görsel kültür hızla gelişen etki alanı nedeniyle özellikle Batı'dan başlayarak ülkemize kadar pek çok ülkede sanat eğitimi programlarında ders olarak yerini almış durumdadır.

Sanatın sosyalizasyonunda öncelikle mevcut durum analizi yapmak gereklidir. Özellikle sanat eğitiminin toplumsal olarak algılanma durumunun güncel verilerinin ülkemiz açısından iyi olduğunu söylemek mümkün değildir. Sosyalizasyon sürecinde, sürece etki eden faktörlerin belirlenmesi gerekir. Bunun için oryantasyon eğitimi ve sürece etki eden dış faktörlerin ve gelecekçi bakış açılarının tespit edilmesi önemlidir. Sanatın ve sanat eğitiminin sosyalizasyon aracı olarak görülmesine ilişkin isteklerden başarılı sonuçlar elde etmek ancak, toplumsal olarak sanat ve eğitiminin gerektirdiği değerlerin içselleştirilmesi ile mümkün olabilir. Çocukluğun ilk evrelerinden itibaren sanat ve sanat eğitimi, öğrenim çağındaki bütün bireylerin sosyalizasyonunda birincil önem taşımaktadır. Çünkü üretilen her sanat ve tasarım eseri toplumda sosyal bir ağ oluşturmaktadır. Bu ağ, bir tür tüketim anlayışı ve yaşam biçimi ile anlatılabilen kültürel bir olgudur. Düşünmeyi, araştırmayı, tasarımı, dönüştürmeyi, üretmeyi ve kendini keşfetmeyi sanat eğitimi ile öğrenen çocuklar ve gençler için sanatın sosyalizasyon aracı olarak düşünülmesi oldukça önemlidir. "Çocuklukta sınırlı olan sosyal öğrenme süreçlerini geniş tutmak gerekir" (Spencer, 2004, 127). Bu sayede bireyler davranış biçimlerini ve tecrübelerini oluşturma sürecine girebilmektedir. Sosyolojik bir konu olmasının yanı sıra sanat yoluyla sosyalizasyon ülkemiz açısından henüz yeterince incelenmiş bir konu olmamakla birlikte, sosyalizasyonun daha çok sanata yönelik bir performansı mümkün olmuştur. Bu performansın yenilikçi sanat eğitimi programları ile zenginleştirilmeye çalışıldığı dikkatlerden kaçmamaktadır. Sanat ve eğitimine yönelik sosyalizasyon sürecinde sosyalizasyon araçlarının ve yenilikçi sanat eğitimi anlayışlarının etkisi dikkati çekmekle birlikte burada kültürel ortam ve ekonomik düzeyin de önemli bir etken olduğu unutulmamalıdır. 
Bugün için kentlerin insanlara sunduğu günlük yaşam olanakları ve yaşam biçimleri, bir çeşit medya sistemleri ve ağları ile yeni anlatıma dönüşmüştür. Birey için oldukça yeni olan ve sürekli gelişen bu durum, dönüşüm kavramı bağlamında tasarım ve sanat olgusuyla güncellenerek geliştirilmektedir. Bu gelişmeye neden olan kavramsal ve kuramsal bileşenler olarak dönüşüm, tasarım ve sonucundaki sanat ve estetik olgusu için düşünülen pedagojik süreçlerin yeniden sosyalizasyon bağlamında güncellenmesi gerekmektedir. Sanatın ve sanat eğitiminin sosyalizasyon için değerini önemseyen kültürel ve pedagojik bileşenlerin sayısının bu kadar yoğun olması konumuz açısından kayda değer sonuçlar olarak dikkate alınmaktadır.

\section{TARTIŞMA VE SONUÇ}

Kültüre dayalı günlük yaşam deneyimleri ve pedagojik yapılanmalar iletişim ve genel olarak medya araçları ölçeğinde mekânın sınırlı imkânlarından bağımsız olarak değerlendirilmek durumundadır. Pedagojik yapılanmalarla yaşam biçimleri arasındaki ilişkinin ölçüsünü belirleyen böylesi etki olanaklarını yeniden tanımlamak gerekmektedir. Bu tanımlamanın belirleyici faktörü olarak sanatın bireysel ve toplumsal öneminden kaynaklanan sosyalizasyon bağlamını tartışmak önemlidir. Sanat eğitiminin yeni pedagojik ilgileri ile gelişen ve dönüşen kültürel yapıya dönük yenilikçi yapısı, toplumsal ve bireysel önemini ve ilişkilerini artırmaktadır. Günümüzde sosyalizasyon aracılarının başat unsurlarından eğitimin temel dayanaklarından birisi olarak sanat eğitiminin bireysel ve toplumsal gerekliliği öne çıkmaktadır. Sanat eğitimi bireyi esas alır. Dolaylı olarak toplumsal bir hedefte sanat eğitiminin amaçlarının gerçekleşip gerçekleşmediği ile ilgili tereddütler ülkemiz açısından önemli bir tartışma konusudur.

Günlük yaşamı oluşturan ve dönüştüren teknoloji, multimedya ve sanatsal bağlamlar sanat eğitiminin önemini birçok yönden tartışmaya açmıştır. İletişim teknolojileri, medya, sanat ve endüstri günümüz toplumsal yapılarını belirleyen bileşik unsurlar olarak dikkat çekmektedir. Disiplenlerarası bir takım karmaşık teknikler soruncunda tasarım olarak ortaya konulan ve sürekli dönüşüme tabi olan nesneler toplumsal yapıları sosyalizasyon ölçeğinde etkilemektedir. Bu bakımdan sanat, sosyalizasyonun bütün araçlarını kapsayabilecek bir karakteri yansıtır. Sanatın, bir kültürel olgu olarak değer görmediği dönemlerde dahi insan varlığının düşünme, yaşama ve iletişim biçimlerini daima dönüştürdüğü bilinmektedir. Sanat aynı zamanda bu dönüşümlerin sosyal, kültürel ve ekonomik etkileri ile de ilgilenmiştir. Buna rağmen ülkemizde sanat ve sanat eğitiminin sosyalizasyon özelliğine yönelik öngörüler için düşünmek oldukça yenidir. Konumuz açısından toplumsal ve kültürel kırılmalar ve dönüşümler, sanat ve toplum ilişkisini, sanat ve tasarım ilişkisinde sosyalizasyonu ve sanat eğitiminde pedagojik dönüşümlere yönelik öngörüleri, tartışma alanları olarak ortaya koymaktadır. Sanatın günümüz toplumları ve kültürleri açısından bir enformasyon aracı olduğu düşünüldüğünde özellikle ülkemiz açısından sanatla sosyalizasyon fikrinin ve uygulamalarının henüz yeterince olgunlaşamadığı dikkati çeker.

Özgül olarak sanat, tek başına sosyalizasyonun bileşeni olabilecek rasyonel bir karakter sergiler. Böylesi bir karakterin toplumsal gerektirmelerinde endüstriyel gelişmelere paralel olarak sanat ve günlük yaşam tasarımlarının yeni oluşturduğu sosyo-kültürel kalıplar, çoklu kültürün etkisiyle kırılarak küresel bir anlam kazanmıştır. Sanatın entelektüel değişimlerin belirleyicisi olduğu yönündeki sosyolojik kanıtlar, toplum ile sanatı birleştirme eğilimini göstermektedir. Düşüncenin ve kültürel eylemlerin göstergesi olarak tanımlanabilen sanat, sosyalizasyon araçlarının bütününü kapsayabilen kültürel bir bileşen durumundadır. "Toplum bir takım roller ağından oluşmaktadır. Fakat bu rollerden bazıları diğerlerine oranla daha çok gereklidir. Önemli olan bu rollerin her kuşaktan yeterli ölçüde alınmasıdır" (Nash, 1989; 85). Sanat uzun vade toplumsal değerleri koruma ve aktarım aracı olmuştur. Bu nedenle, sanatı ve sanat eğitimini temel sosyalizasyon aracı olarak düşünmeyi, günümüzün sosyal ve kültürel 
gerektirmelerinden biri olarak değerlendirmek durumundayız. Kültürel yaşantılar açısından bireysel ve sosyal farklılıkların öne çıktığı günümüzde sanat ve sanat eğitimi birey için daha anlatımcı ve sosyolojik bir olgu durumundadır. Sanat eğitimine yönelik olarak böylesi bir sosyal bağlam hakkında çözümlemeler yapmak ve sosyolojik tespitlerde bulunmak, sanat yoluyla sosyalizasyonun kültürel çerçevesini çizmeye yardımcı olur. Illetişim ve tüketim kültürüne bağlı çoğulcu medya tasarımlarının evreninde yaşam süren günümüz bireyinin, sosyal kurgusal anlatıları çözümleme ve değere dönüştürebilme yetkinliğine sanat eğitimi ile ulaşarak toplumsallaşabileceği unutulmamalıdır. Öte yandan kültürel kırılmalar ve sosyal dönüşümleri hareketlendiren yeni medya endüstrisi sanat ve tasarımın referans alındığı üretim süreciyle kendine özgü bir form kazanmıştır. Yeni medya endüstrisinin sanat ve estetiği temel aldığı bu süreçte, sanatın endüstriyel karakteri gelişme göstermektedir.

Ülkemiz açısından sosyalizasyon bağlamında sanat eğitiminin pedagojik dönüşümlerinin ve disiplinler arası etkileşim olanaklarının gözden geçirilmesi gerekir. Sonuç olarak sanat yoluyla sosyalizasyon, sanatın ortaya çıktığı andan itibaren süre gelen bir olgu olsa $\mathrm{da}$, bu olgunun pedagojik olarak topluma yansıma biçimleri her dönem için de önemli bir tartışma konusu olmuştur. Eğitim sistemlerinde, sanat eğitimin sosyalizasyonun önemli bir parçası ve gereği olduğunun rasyonel olarak belirlenmesi gerekmektedir. Öte yandan sanat eğitiminin doğasının ve kültürünün yeni pedagojik dönüşümlerle yeniden ele alınması da bu bakımdan önemsenmelidir. Sanatın sosyolojik yapısı gereği sanat eğitiminin sosyalizasyonun bir bileşeni olduğu düşüncesi her şeyden önce, teknolojik faktörlerin yanı sıra, toplumsal ve kültürel kırılmalar sonucunda ortaya çıkan ve etkili olabilen bir olgu olarak gelişme göstermektedir. Günümüz dünyasında sanat değişimin mimarı, dönüşümün sosyo-kültürel ajanı olarak dikkati çekmektedir. Toplumsal yapıyı ve kültürü fazlasıyla etkileyen yeni medya, günümüz bireylerinin bir yaşam biçimi ve anlatım aracı olmuş durumdadır. Yeni medya endüstrisi ve sanatı ile şekillenen günümüz sosyolojik yapılarında, sanatın ve sanat eğitiminin belirleyici rolü giderek artmaktadır.

\section{KAYNAKLAR}

Arslantürk, Z. ve Amman, M. T. (2013). Sosyoloji, 9. Baskı, İstanbul: Çamlıca.

Becker, H. S. (1989). "The Socialization of an Artist: The American Composer", Art and Society Reading in The Sociology of the arts, Arnold W. Foster and Judith R. Blau (Ed.), III. Series, State University of New York Press, Albany, Printed in the USA. (pp.41-54).

Bilgili, C. ve Akbulut, N. T. (2011). Kırılan Kalıplar1 - Kitle Illetişim ve Kültürel Dönüşüm, İstanbul: Beta.

Bozkurt, N. (2013). Sanat ve Estetik Kuramları, Ankara: Sentez.

Buyurgan, S. (2008). Sanat Eğitimi ve Öğretimi, İstanbul: Pegem Akademi.

Büyüköztürk, Ş., Kılıç, E. vd. (2008). Bilimsel Araştırma Yöntemleri, Ankara: Pegem Akademi.

Decenzo, D. A. and Robbins, S. P. (2011). "Fundamentals of Human Resource Management", Chapter 8, Socializing, Orienting, and Developing Employees, Inc.:USA.https://docs.google.com (Erişim Tarihi: 201417 Mayıs).

Dellaloğlu, B. F. (2007). Frankfurt Okulu'nda Sanat ve Toplum, İstanbul: Say.

Doğan, i. (2009). Sosyoloji: Kavramlar ve Sorunlar, 8. Baskı, Ankara: Pegem Akademi.

Erbay, M. (2013). Sanat Eğitimi Üzerine, İstanbul: Beta. 
Foster, A. W. (1989). Art and Society Reading in The Sociology of the arts, Arnold W. Foster and Judith R. Blau (Ed.), III. Series, State University of New York Press, Albany, Printed in the USA.

Freedman, K. (2003) "Socıal Perspectıves of Art Educatıon in The U.S.: Teachıng Visual Culture In A Democracy", This article was originally published in Studies in Education, Volume 42, Issue 4, InJAE 1.3 (C) NTAEC, Northern Illinois University.

Giddens, A. (2005). Sosyoloji, (Haz. Cemal Güzel), Ankara: Ayraç.

Gauvain M. and Perez S. M. (2007). "The Socialization of Cognition", Handbook of Socialization Theory and Research, Joan E. Grusec, Paul D. Hastings (Ed.), A Division of Guilford Publications, Inc., Printed in the USA. (pp.588-600).

Macionis, J. J. (2013). Sosyoloji, 13. Baskı, (Çev. Vildan Akan), Ankara: Nobel.

Mayer F. (2004). Socialization, Routledge is an imprint of the Taylor \& Francis Group, Printed and Bound in Great Britain.

Nash, J. D. (1989). "The Socialization of an Artist: The American Composer", Art and Society Reading in The Sociology of the arts, Arnold W. Foster and Judith R. Blau (Ed.), III. Series, State University of New York Press, Albany, Printed in the USA. (pp.85-96).

Newman, D. M. (2013). Sosyoloji: Günlük Yaşamın mimarisini keşfetmek, 3. Baskı, (Çev. A. Arslan), Ankara: Nobel.

Punch, K. F. (2011). Sosyal Araştırmalara Giriş: Nicel ve Nitel Yaklaşımlar, (Çev. D. Bayrak, H.B. Arslan, Z. Akyüz), Ankara: Siyasal Kitabevi.

Shiner, L. (2010). Sanatın İcadı, (Çev. İsmail Türkmen), İstanbul: Ayrıntı.

Spencer P. (2004). "The Function of Ritual in the Socialization of the Samburu Moran", Socialization, (Anthropology and Ethnography), Rautledge Library Editions, Routledge is an imprint of the Taylor \& Francis Group, (pp.126-160).

Tezcan, M. (1993). Sosyolojiye Giriş, 7. Baskı, Ankara: Anı.

Tolstoy, L. N. (2013). Sanat Nedir?, 5. Baskı, Hasan Ali Yücel Klasikler Dizisi, (Çev. M. Beyhan), İstanbul: Türkiye İş Bankası Kültür Yayınları.

Ulusoy, D. (1997). "Modern Toplumda Sanat: Güzel Sanatlarda Uyum ve Uyumsuzluk", Ekonomik Yaklaşım, 8(27), Ankara.

Yılmaz, M. G. (2009). "Sanat ve Diğer Disiplinlerle Iliş̧kisi", Sanat Eğitimi ve Görsel Sanatlar Öğretimi İçinde, A. O. Alakuş, L. Mercin (Ed.), (ss. 39-56). Ankara: Pegem Akademi. 


\section{SUMMARY}

The conceptions of culture and virtue are the essential components of sociology which are necessary to be identified as individual in a society. Being an individual in a society and having a cultural function as a part of this society come true by socialization. Socialization, continuing with processes of identity development and perception and identification of self and universe, teaches individuals to explore themselves, to care about interests, attitudes and behaviors necessary for the society and virtues and to live for them. In this way, socialization makes all the individuals as culture producer. So, it is important to determine the disciplines which socialization is affected theoretically and conceptually in order to develop this process effectively and to identify the process as sustainable and interactive for the society and the individuals. In the period in which cultural, sociological and pedagogic affairs are interdisciplinary interactive more than before, facts introduced universally by the cultural and sociological breakups and transformation have made the integration of disciplines pedagogically and socially compulsory. For example, the assessment of daily experiences and lifestyles socially and culturally shows "social construction" which can be in relation to art and design dominated by visuality, visual designs and eventually visual culture and consumption of behaviors of individuals. The structure of art which make individuals gain virtues as communication competency, critical thinking and problem solving in addition to its effect to inner world of individual, is a clue which makes the integration of socialization and art education compulsory for socialization. The structure of art and art education related to culture is a satisfactory context to make art as a vehicle for socialization.

The process of socialization is important with its development as a holistic affair. There is art in the preface of social development and modern civilization. Art as a concrete form of interaction of cultures and virtues from past to today and a necessity in all the areas of life shows constitutional unity involving all needs of individual. Art, making communication aesthetics with audio and stylistic ways, motivates the humanity in the way of perfection. Art makes it possible for people of last generation to experience the feelings of people from the earlier ages and people who are leader and futurist in their own age. And as the evolution of information, elimination of wrong and unnecessary information by real and necessary information, the evolution of feelings comes true by art, elimination of feelings which are low level, less good and less necessary for welfare of people by feelings necessary for welfare of people. Art is a mean for development of people's feelings. The methods people express their feelings and thoughts are indicator of social development. Such a parameter which is possible with the social value of art is related to contexts forming socialization. The social relation of modern people with new media systems is an important issue which supports the socialization by art indirectly. Socialization by art and art education is a special situation in our study and country. The formation of social constructions and interactions with new media shows an image which lifestyles and perception of consumption are in relation with art and design industry. In the relation of art which is necessary for the social construction and social balance and socialization which enables individual to be a social being, it is essential for our country to look art and art education from more contemporary and sociological view.

The cluster of virtues gained individually includes the effects related to the process of socialization. The cultural shadows of virtues can be studied in terms of contemporary consumption references of social pattern when it is possible to evaluate them subjectively and objectively. Within this context, the new culture, social pattern, media and its representation forms have confined the communication and daily routines to a process of cultural transformation centered in design and art along with communication. Such a social pattern and communication forms in which the relation of art and design stand out have some notable effects on pedagogical transformations. These effects bring structural transformation statements for art and its teaching, foresights and expectations into question in addition to promoting the social strength of art and its effects on many disciplines. The aim of this study is to try to define -in socialization terms- the new expressive patterns of structural transformation which can be concluded as a paradigm transformation in art teaching processes in an era in which the foresights that can be defined as the new patterns of teaching art and that happen in compliance with pedagogical and cultural transformation, and ever-changing hypothetical and institutional patterns of daily life and industry are broken and reshaped according to current conditions. 